\title{
MICROSCOPICAL AND MICROMECHANICAL FEATURES OF HIGH PERFORMANCE CONCRETE CONTAINING LOW LEVELS OF FLY ASH
}

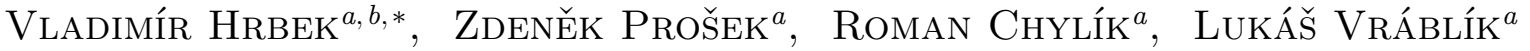 \\ ${ }^{a}$ Czech Technical University in Prague, Faculty of Civil Engineering, Thákurova 7, 16629 Prague, \\ Czech Republic \\ ${ }^{b}$ Institute of Theoretical and Applied Mechanics AS CR, v.v.i., Prosecká 76, 19000 Prague 9, Czech Republic \\ * corresponding author: vladimir.hrbek@fsv.cvut.cz
}

\begin{abstract}
Alkali activated fly ash is a widely used admixture to the concrete. Due to the pozzolanic activity, the fly ash can replace up to 60 mass percentage. The impact of fly ash on the concrete depend on the level of it content, i.e. in small levels it improves the macro-mechanical properties and durability as well as chemical resistance. On the other side, fly ash admixture negatively influence the set time and cause slow development of strength. Therefore, the effect of small fly ash admixture levels on the micro-structure of high performance concrete (HPC) is discussed in this study.
\end{abstract}

KEYWORDS: High performance concrete, CCP, fly ash, grid indentation, spectral deconvolution SEM, EDX, image analysis, structure, effective modulus.

\section{INTRODUCTION}

The high performance concrete (HPC) became a commonly used building material in civil over last years due to increased demands on construction costs reduction, quality of building materials, prolonged service life of constructions, etc. Compare to ordinary concrete, additional admixtures are added to the mixture, such as fly ash, providing specific features of hardened concrete.

Fly ash (FA) falls into the category of coal combustion products (CCPs) that are produced from either hard or brown coal burning in coal-fired power stations. It is obtained from the gases of furnaces fired with coal or lignite at 1100 to $1400^{\circ} \mathrm{C}$ by electrostatic or mechanical precipitation of dust-like particles. FA is defined as fine powder, mainly composed of spherical glassy particles. Its chemical composition and pozzolanic and/or latent hydraulic properties depend upon the type of boiler and the type of burned coal. In general, fly ash contains significant quantities of crystalline and amorphous silicon dioxide $\left(\mathrm{SiO}_{2}\right)$, aluminum oxide $\left(\mathrm{Al}_{2} \mathrm{O}_{3}\right)$, calcium oxide $(\mathrm{CaO})$ and traceable amounts of other elemnets, such as magnesium, chrome, mercury etc. [1, 2]

According to statistics of European Coal Combustion Products Association (ECOBA) from 2016 [3], production of coal combustion products (CCPs) in EU 15 countries reached 40.33 million tons and was estimated over 105 million tons in EU 28 countries. Wast majority of CCPs (63.8\%, approx. 25.73 million tons) consists of FA and its utilization in the construction industry is currently around $43 \%$ (11.4 million tons). Individual CCPs production in EU 15 group is depicted in Fig. 1a. Detailed statistics from EU 28 group are not reliable due to vague characterization of CCPs and insufficient data collection.

Statistics from American Coal Ash Association (ACAA) obtained in 2016 [4], show overall CCPs production of 107.43 million tons, where only $35.2 \%$ (37.82 million tons) is represented by fly ash and $59.9 \%$ of it (22.63 million tons) is further used in other industries. It is worth mentioning, that overwhelming majority $(75.3 \%, 17.04$ million tons) of fly ash in USA is used in blend cement, concrete and concrete products. Fly ash specification and comparison to Portland cement, according to American standard (ASTM C618), are summarized in Tab. 2

In Czech Republic, according to Association for the District Heating of the Czech Republic (ADH CR) and ASVEP from 2014, approximately 13 million tons per year of CCPs are produced, from which 9.24 million tons $(71.1 \%$ of estimated production) are classified as fly ash (Fig. 1b) . Compare to EU 15 countries, Czech republic utilize most of CCPs, $59 \%$, are used as surface mine backfill and just $11 \%$ for cement, concrete and masonry production. Even though data of average chemical composition with respect to national standard are not available, specific oxide mass percentage of fly ash obtained from different power plants are presented in Tab. 2 .

National standard CSN EN 197-1 recognizes fly ash, based on chemical composition, as silica (V type) and calcium fly ash (W type). Their average chemical composition, according to [1, is presented in Tab. 2

Silica fly ash particularly contains silicon dioxide $\left(\mathrm{SiO}_{2}\right)$ and aluminum oxide $\left(\mathrm{Al}_{2} \mathrm{O}_{3}\right)$, where content of active $\mathrm{SiO}_{2}$ should be over $25 \%$ of weight. It also includes more than 10 weight $\%$ of active calcium oxide and free form $\mathrm{CaO}$ should not exceed 1.0 weight $\%$. Its use, when free $\mathrm{CaO}$ (lime) is in range of 1.0 to 2.5 weight $\%$, is limited according to the standard. 


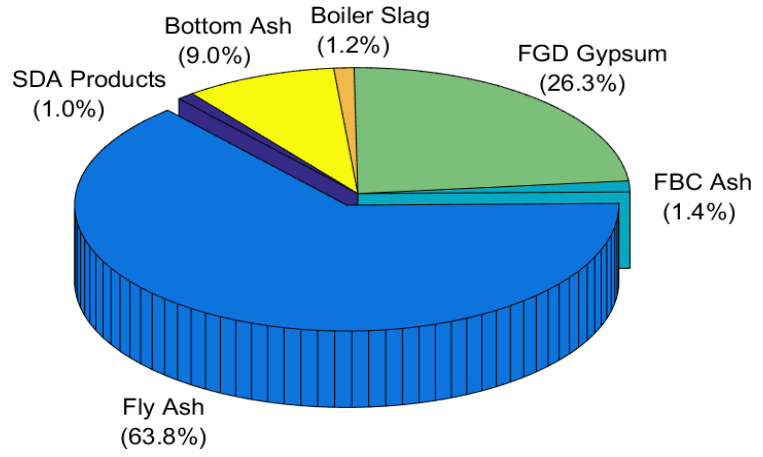

(a) CCPs production in EU15, 2016.

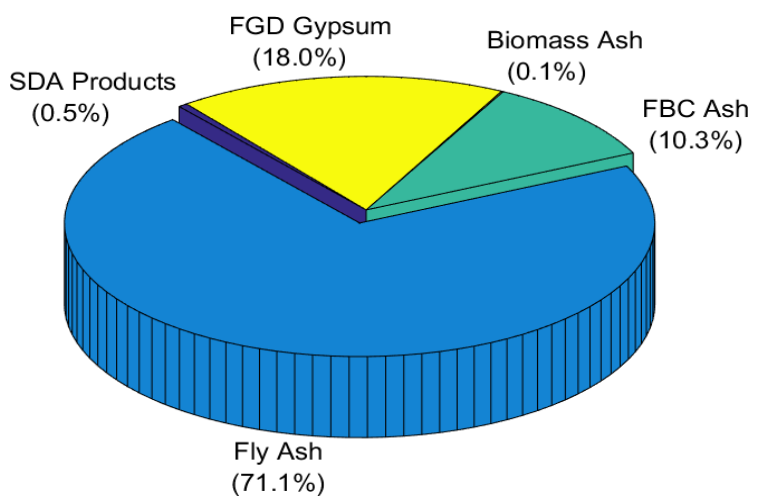

(b) CCPs production in Czech republic, 2014.

FIgURE 1. Statistics of CCPs production. (note: SDA - Semi Dry Absorption, FGD - Flue Gas Desulphurization, FBC - Fluidized Bed Combustion)

$\mathrm{V}$ type fly ash reacts with calcium hydroxide $\left(\mathrm{Ca}(\mathrm{OH})_{2}\right)$, which is present due to cement hydration, while generating silica hydrates and calcium aluminates. In stage of cement hydration initiation can its particles serve as nucleation centers for hydration products crystallization.

Calcium fly ash consists of $10-15$ weight $\%$ of active $\mathrm{CaO}$ and more than 25 weight $\%$ of active $\mathrm{SiO}_{2}$. Compare to silica fly ash, the concentration of alkali and sulfates is higher in W type fly ash and, when calcium hydrate and water is present, it displays pozzolanic and/or hydraulic behavior [5, 6].

Fly ash replacement at various levels of the cementitious binder and its impact on hardened composite has been observed on macroscopical level in many studies. Higher levels of fly ash addition (30 to 50 weight\% replacement of cement) have been in past used mostly in massive structures, like foundations and dams, to control heat generation of the mixture hydration. In recent years, high replacement levels (40 to 60 weight\%) used in structural applications produced concrete with increased mechanical properties and durability 77. Dependency of fly ash containment (both low and high levels of replacement of cement) and evolution of concrete strength in time are described in [8, 9].

The improvements of fresh concrete mixture containing fly ash addition, specifically the effect on workability and possible decrease of water-cement ratio, as well as impact on segregation of cement paste and aggregate are discussed in [10-12] .

Positive impact of the fly ash on shrinkage mitigation depends on two major facotrs, size and size distribution of fly ash particles and water requirements on the mixture. As pointed out in [13, 14, application of $50 \%$ replacement of cement by fine fly ash led to the shrinkage reduction by $30 \%$. Comparably, when coarse fly ash replacement is used, less reduction of drying shrinkage is observed.

Other aspect of fly ash addition is its positive effect on permeability and chemical resistance concrete composite. As shown in [15 17, low levels of fly ash replacement decrease the permeability up to $10-15 \%$ compare to conventional concrete. However, as in case of more than 50 cement weight\% replacement, higher permeability (compare to control specimens) can be observed. On the other hand, significant reduction of chloride permeability (i.e. improvement of chemical resistance), as well as impact on pores size and distribution, with each increment of fly ash replacement volume [18.

\section{MATERIALS, SAMPLE PREPARATION}

For purpose of this study, 4 mixtures were selected for testing, referential mixture (REF) and 3 modified mixtures containing 10, 20 and 30 weight $\%$ fly ash replacement of cement (FA10, FA20, FA30). Ingredients of referential mixture consisted of cementitious binder (CEM I 42.5 R - Mokrá), filler (crushed unwashed basalt aggregate of particle sizes $0-4,4-8$ and 8 $16 \mathrm{~mm}$ ), water and poly-carbonate based plasticizer (Stachement, Stachema). Mixture compositions can be found in Tab. 1

\begin{tabular}{lcccc}
\hline Component & REF & FA10 & FA20 & FA30 \\
\hline CEM 42.5 R & 800.0 & 720.0 & 640.0 & 560.0 \\
Aggreg. 0 - 4 & 730.0 & 730.0 & 730.0 & 730.0 \\
Aggreg. 4 - 8 & 390.0 & 390.0 & 390.0 & 390.0 \\
Aggreg. 8 - 16 & 320.0 & 320.0 & 320.0 & 320.0 \\
Fly ash & 0.00 & 80.0 & 160.0 & 240.0 \\
Water & 210.0 & 197.4 & 184.8 & 172.2 \\
Plasticizer & 32.0 & 33.8 & 29.6 & 29.5 \\
\hline
\end{tabular}

TABle 1. Compositions of tested mixtures in $\left[\mathrm{kgm}^{-3}\right]$

Specimens (cubes of $100 \mathrm{~mm}$ dimension) were stored in water in laboratory conditions $\left(20-22^{\circ} \mathrm{C}\right)$ to ensure adequate cement matrix hydration and to reduce rheologic changes and degradation of tested materials. Furthermore, samples were prepared, using grinding and polishing media, for purpose of electron microscopy and indentation. Due to mechanical and structural heterogeneity of the composite, preparation method reducing selective abrasivity was adopted. By using this method, both adequate roughness of the specimens surface and compact interface transition zone between aggregate and cement matrix were secured. 


\begin{tabular}{cccccccc}
\hline Oxide & Class F & Class C & V type & W type & Detmarovice & Hodonin & Portland cement \\
\hline $\mathrm{SiO}_{2}$ & 50.0 & 40.0 & 51.4 & 39.4 & 50.4 & 31.6 & 23.0 \\
$\mathrm{Al}_{2} \mathrm{O}_{3}$ & 26.0 & 17.0 & 30.0 & 30.0 & 25.5 & 17.0 & 4.0 \\
$\mathrm{Fe}_{2} \mathrm{O}_{3}$ & 7.0 & 6.0 & 4.2 & 2.2 & 7.9 & 6.6 & 2.0 \\
$\mathrm{CaO}$ & 9.0 & 24.0 & 1.3 & 11.6 & 4.8 & 29.4 & 64.0 \\
$\mathrm{MgO}$ & 2.0 & 5.0 & 1.4 & 1.4 & 2.8 & 3.7 & 2.0 \\
$\mathrm{SO}_{3}$ & 1.0 & 3.0 & 0.6 & 3.8 & 0.7 & 7.8 & 2.0 \\
\hline
\end{tabular}

TABLE 2. Oxide analysis in weight percentage [\%] of fly ashes an Portland cement

\section{Methods And DATA PRocessing}

The testing of described high performance concrete specimens was performed with two independent methods, scanning electron microscopy (SEM) and grid nano-indentation. In order to overcome heterogeneous complexity, both methods were implemented on two main levels of the composite- matrix without basaltic aggregate and transition zone between aggregate and matrix with limited occurrence of clinker. This prevented duplicity of obtained data from different phases in the material with close mechanical and/or structural features (such as aggregate and clinker etc.).

\subsection{SCANNING ELECTRON MICROSCOPY AND IMAGE ANALYSIS}

Scanning electron microscope Mira II LMU (Tescan corp., Brno) equipped with EPMA was used for purpose of microstructure investigation and phase recognition of HPC samples. Chemical composition (i.e. elemental analysis) of each phase was established by energy-dispersive X-ray spectroscopy (EDX).

This method is precise for determination of weight percentage representation of each chemical element in measured area, nevertheless it is greatly time consuming and covers limited percentage of sample. In general, energy of back-scattered electron is dependent on atomic number $\mathrm{Z}$ of the element which is relevant to brightness of the phase in BSE diagram. This led to direct use of image analyses of back-scattered electron micro-graphs which provided effective description of composite matrix. Based on rough estimate of number of phases from low number of EDX measurement, it possible to determine proper number of phases and their gray-scale range from histogram of several BSE SEM graphs. Furthermore it is possible numerically quantify percentage representation of each phase and/or convert the diagram onto RGB spectrum image for better imagination of material structure.

In case of aggregate-matrix transition zone, twostage image analyses was applied on BSE diagrams. The sodium-calcium feldspar forming a structure of basalt aggregate is on gray-scale close to phases present in matrix. Differential image analysis than consists of main binding phases (C-S-H gel) separation and identification of other phases in next step of the process based on their internal heterogeneity.

\subsection{QUASI-STATIC INDENTATION AND SPECTRAL DECONVOLUTION}

Elastic micro-mechanical parameters of individual phases were established usnig grid indentation ( $\mathrm{Ti}$ 700 series, Hysitron Inc.). Principle of indendentation technique is based on dependency of probe propagation with respect to the recorded material response. The force-displacement record is further processed and the mechanical properties are calculated from the unloading part of the record. Incorporated errors of the measurement, such as creep and visco-elasticity of measured phases, are avoided by appropriate test setup [19 25].

The implemented indents were displacement driven with maximum depth of $150 \mathrm{~nm}$. For both levels of measurement, load function consisting of loading and unloading over 5 seconds with inserted holding time segment lasting 60 seconds in which maximum depth was held to ensure limited impact of material creep. The indents, again for both levels of investigation, were placed in 21 by 21 grind with mutual separation of $10 \mu \mathrm{m}$. Due to material level separation and indentation setting, grid indentation criteria of heterogeneous material are met [26-30].

Effective modulus of each individual phase present in the composite were derived based on spectral deconvolution of indentation data. The process of spectral deconvolution, unlike statistical deconvolution, takes into account mutual interaction of phases (such as interaction of soft C-S-H gel and tough clinker) and data interference. The deconvolution procedure was implemented individually on both levels of investigated material and and overall effective features were established from merged normalized histograms of indentation data. Maximum allowed divergence between structural and mechanical percentage representation of measured data did not exceed $2.5 \%$.

\section{Results}

The results of previously described methods and data analysis are stated in this section. Mechanical features of individual phases, derived by spectral deconvolution of indentation measurements (Fig. 2), are summarized in Tab. 3. The structural description of the composite, in means of individual phase percentage representation, was acquired using image analysis of SEM BSE micro-diagrams (Tab. 4 ). 


\begin{tabular}{cccclcc}
\hline Sample & ITZ & LD CSH & \multicolumn{1}{c}{ HD CSH } & \multicolumn{1}{c}{ Portlandite } & \multicolumn{1}{c}{ Clinker } & Aggregate \\
\hline FA10 & $16.74 \pm 2.42$ & $33.45 \pm 5.89$ & $54.54 \pm 7.63$ & $84.92 \pm 14.07$ & $142.13 \pm 13.34$ & $154.86 \pm 4.89$ \\
FA20 & $16.48 \pm 2.12$ & $34.95 \pm 5.36$ & $54.99 \pm 6.38$ & $88.63 \pm 13.16$ & $140.22 \pm 17.42$ & $163.32 \pm 7.81$ \\
FA30 & $18.80 \pm 4.40$ & $35.62 \pm 5.87$ & $57.72 \pm 6.40$ & $86.17 \pm 7.59$ & $127.57 \pm 24.85$ & $161.54 \pm 8.28$ \\
REF & $17.34 \pm 2.52$ & $31.08 \pm 4.59$ & $45.07 \pm 2.61$ & $81.60 \pm 18.55$ & $128.36 \pm 6.23$ & $162.78 \pm 5.87$ \\
\hline
\end{tabular}

TABLE 3. Indentation modulus $\left.E_{r}[\mathrm{GPa}]\right)$ of concrete composites containing fly ash replacement
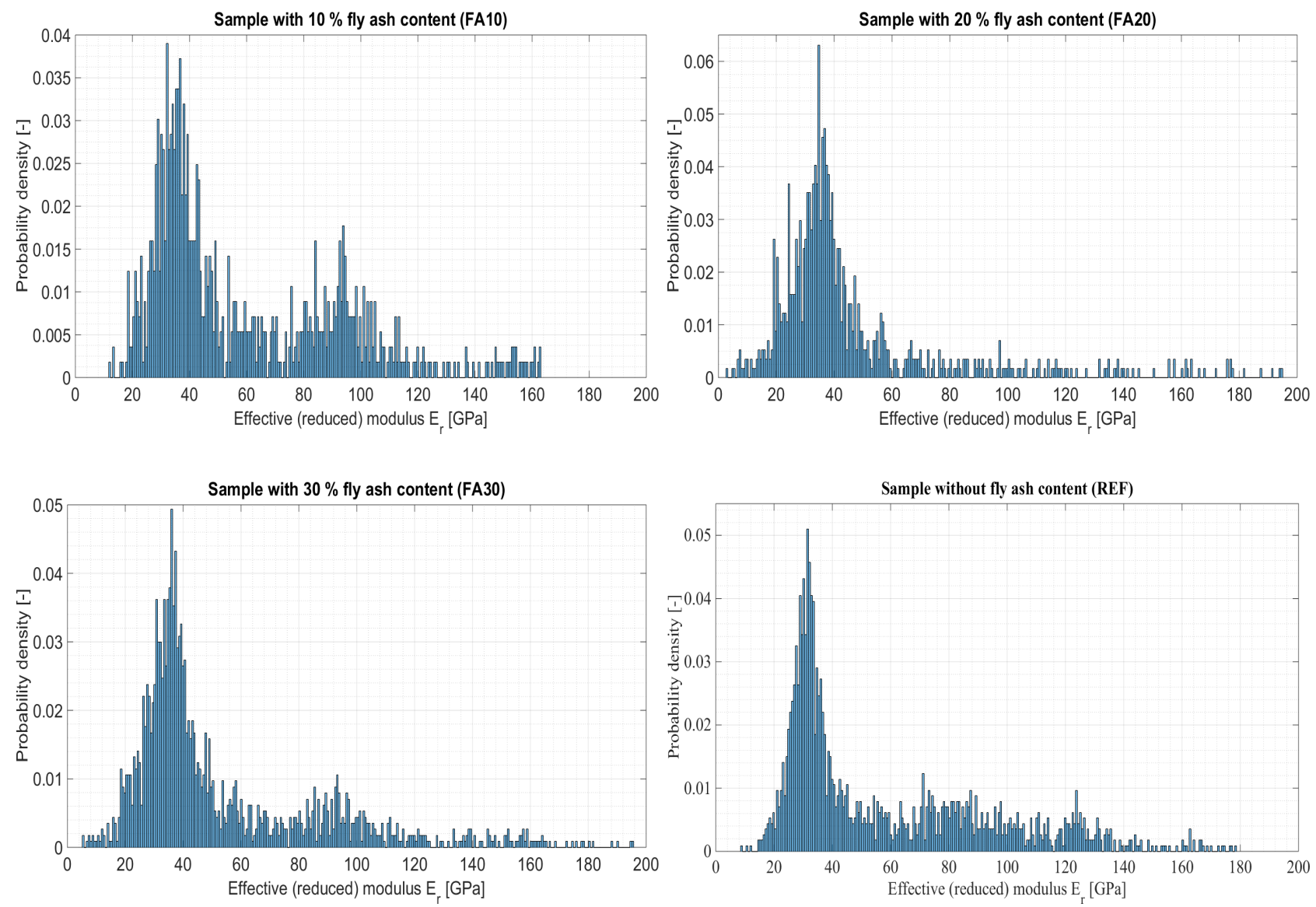

FIGURE 2. Histograms of indentation modulus $E_{r}$.

\begin{tabular}{ccccccc}
\hline Sample & Porosity & LD CSH & HD CSH & Portlandite & Clinker & Aggregate \\
\hline FA10 & 1.19 & 9.61 & 15.34 & 11.77 & 4.20 & 57.89 \\
FA20 & 1.56 & 12.25 & 13.96 & 8.50 & 2.93 & 60.78 \\
FA30 & 2.34 & 13.48 & 13.79 & 8.40 & 2.81 & 59.18 \\
REF & 1.50 & 15.82 & 15.43 & 6.55 & 4.18 & 56.52 \\
\hline
\end{tabular}

TABLE 4. Percentage representation of individual phases in composite [\%]

\section{Conclusion}

From the indentation results of composites on microscopical level and phase representation (based on image analysis of SEM BSE diagrams), following conclusions can be stated:

- lower rates of fly ash replacements decreased interfacial transition zone modulus by $3.6 \%$ for FA10 sample and by $5.2 \%$ in case of FA20 sample while $8.4 \%$ increase can be observed for FA30 specimen.
- the indentation modulus of both CSH phases (low and high density) are increased in all fly ash replacements. The most influential is $30 \%$ fly ash content, where LD CSH modulus is up $14.6 \%$ and HD CSH up $28.1 \%$.

- the increase of calcium hydrate (portlandite) micromechanical performance by fly ash additions is up to $8.6 \%$ in case of FA20 sample.

- except the lowest fly ash replacement (FA10), fly 
ash addition increase the micro- and nano- porosity.

- the representation of both $\mathrm{CSH}$ phases is significantly decreased, while calcium hydrate (portlandite) percentage increased (especially in $10 \%$ fly ash replacement sample).

The early stage fly ash containing concrete composite project lower macro-mechanical properties, even though the micro-mechanical features of the matrix are elevated with the fly ash addition. The effect can thus be linked to the structural changes of each composite (mainly to increased porosity and lower CSH phases representation). The impact of fly ash addition on the interfacial transition zone is not conclusive, due to inconsistent aggregate sizes in the measurements. Further investigation of fly ash replacement on the ITZ is proposed.

\section{LIST OF SYMBOLS}

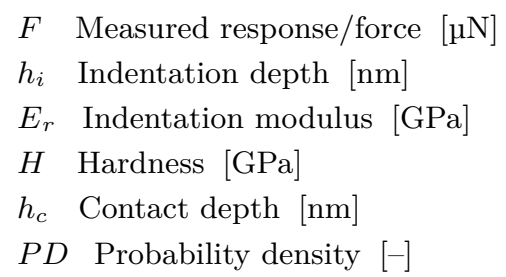

\section{ACKNOWLEDGEMENTS}

The research is financially supported by Czech Technical University in Prague - project SGS17/168/OHK1/3T/11 and by the Czech Science Foundation research project 17-19463S. The support is gratefully appreciated.

\section{REFERENCES}

[1] B. Pacewska, G. Blonkowski, I. Wilinska. Investigations of the influence of different fly ashes on cement hydration. Journal of Thermal Analysis and Calorimetry 86 (1):179-186, 2006. DOI:10.1007/s10673-005-7136-7.

[2] A. Korpa, T. Kowald, R. Trettin. Hydration behavior, structure and morphology of hydration phases in advanced cement-based systems containing micro and nanoscale pozzolanic additives. Cement and Concrete Research 38 (7):955-962, 2008. DOI:10.1016/j.cemconres.2008.02.010

[3] European Coal Combustion Products Association e.V statistics and ecoba e.V. Electronic source, http://www.ecoba.com/index.html

[4] ACAA 2016 CCP Survey Results, American Coal Ash Association. Electronic source, https://www.acaa-usa.org

[5] F. Caldas-Vieira, H. J. Feuerborn, A. Saraber. European Product Standards, Update on status and changed with relevance to CCPs. In proceedings of World of Coal Ash conference 38 (7):22-25, 2013. Kentucky, USA.

[6] L. K. A. Sear. Fly ash standards, market strategy and uk practice. In proceedings of International Ash Utilization Symposium 38 (7):22-25, 8/2001. University of Kentucky, Kentucky, USA.
[7] V. M. Malhotra, P. K. Mehta. High-performance, high-volume fly ash concrete: materials, mixture proportioning, properties, construction practice, and case histories. Journal of Thermal Analysis and Calorimetry Ottawa, Canada: Supplementary Cementing, ISBN 0-9731507-0-X, TRN: 000600211.

[8] M. Sumer. Compressive strength and sulfate resistance properties of concretes containing class $f$ and class c fly ashes. Construction and Building Materials 34:531-536, 2012. DOI:10.1016/j.conbuildmat.2012.02.023

[9] R. Siddique. Performance characteristics of high-volume Class F fly ash concrete. Cement and Concrete Research 34 (3):487-493, 2004. DOI:10.1016/j.cemconres.2003.09.002

[10] Z. Yao, X. Ji, P. Sarker, et al. A comprehensive review on the applications of coal fly ash. Earth-Science Reviews 141:105-121, 2015. DOI:10.1016/j.earscirev.2014.11.016

[11] M. Berndt. Properties of sustainable concrete containing fly ash, slag and recycled concrete aggregate. Construction and Building Materials 23 (7):2606-2613, 2009. DOI:10.1016/j.conbuildmat.2009.02.011

[12] C. Pellegrino, V. Gaddo. Mechanical and durability characteristics of concrete containing eaf slag as aggregate. Cement and Concrete Composites 31 (9):663671, 2009. DOI:10.1016/j.cemconcomp.2009.05.006

[13] C. Atis. High-volume fly ash concrete with high strength and low drying shrinkage. Journal of Materials in Civil Engineering 15 (2):153-156, 2003. DOI:10.1061/(ASCE)0899-1561(2003)15:2(153).

[14] P. Chindaprasirt, S. Homwuttiwong, V. Sirivivatnanon. Influence of fly ash fineness on strength, drying shrinkage and sulfate resistance of blended cement mortar. Cement and Concrete Research 37 (7):1087-1092, 2004. DOI:10.1016/j.cemconres.2003.11.021

[15] S. Supit, F. Shaikh. Durability properties of high volume fly ash concrete containing nano-silica. Material and Structures 48 (8):2431-2445, 2015. DOI:10.1617/s11527-014-0329-0.

[16] F. Shaikh, S. Supit. Compressive strength and durability properties of high volume fly ash (HVFA) concretes containing ultrafine fly ash (UFFA). Construction and Building Materials 82:192-205, 2015. DOI:10.1016/j.conbuildmat.2015.02.068.

[17] A. Mardani-Aghabaglou, O. Andic-Cakir, K. Ramyar. Freeze-thaw resistance and transport properties of high-volume fly ash roller compacted concrete designed by maximum density method. Cement and Concrete Composites 37 (1):259-266, 2013. DOI:10.1016/j.cemconcomp.2013.01.009

[18] P. Chindaprasirt, C. Chotithanorm, H. Cao, V. Sirivivatnanon. Influence of fly ash fineness on the chloride penetration of concrete. Construction and Building Materials 21 (2):356-361, 2007. DOI:10.1016/j.conbuildmat.2005.08.010.

[19] J. W. Harding, I. N. Sneddon. The Elastic Stresses Produced by the Indentation of the Plane Surface of a Semi-Infinite Elastic Solid by a Rigid Punch. Mathematical Proceedings of the Cambridge Philosophical Society 41 (1):16-26, 1945. DOI:10.1017/S0305004100022325 
[20] W. Oliver, G. M. Pharrr. An Improved Technique for Determining Hardness and Elastic Modulus Using Load and Displacement Sensing Indentation Measurements. Journal of Material Research 7 (6):1564-1583, 1992. DOI:10.1557/JMR.1992.1564.

[21] J. Woirgard, J. C. Dargenton. An Alternative Method for Penetration Depth Determination in Nanoindentation Measurement. Journal of Material Research 12 (9):2455-2458, 1997. DOI:10.1557/JMR.1997.0324.

[22] J. L. Hay, G. Pharr. ASM Handbook Volume 8: Mechanical Testing and Evaluation. 10th edition pp. 232-243, 2000.

[23] G. M. Pharrr, A. Bolshakov. Understanding Nanoindentation Unloading Curves. Journal of Material Research 17 (10):2660-2671, 2002. DOI:10.1557/JMR.2002.0386

[24] W. Oliver, G. M. Pharrr. Measuring of Hardness and Elastic Modulus by Instrumented Indentation: Advances in Understanding and Refinement of Methodology. Journal of Material Research 19 (1):3-20, 2004. DOI:10.1557/jmr.2004.19.1.3

[25] A. C. Fischer-Cripps. A Simple Phenomenological Approach to Nanoindentation Creep. Journal of Material Science and Engineering A 385 (1-2):74-82, 2004. DOI:10.1016/j.msea.2004.04.070

[26] G. Constantinides, K. R. Chandran, F.-J. Ulm, K. V. Vliet. Grid Indentation Analysis of Composite Microstructure and Mechanics: Principles and Validation. Journal of Material Science and Engineering A 430 (1-2):189-202, 2006. DOI:10.1016/j.msea.2006.05.125
[27] F.-J. Ulm, M. Vandamme, C. Bobko, et al. Statistical Indentation Techniques for Hydrated Nanocomposites: Concrete, Bone and Shale. Journal of the American Ceramic Society 90 (9):2677-2692, 2007. DOI:10.1111/j.1551-2916.2007.02012.x

[28] O. Bernard, F.-J. Ulm, E. Lemarchand. A multiscale micromechanics -hydration model for the early-age elastic properties of cement-based materials. Cement and Concrete Research 33 (9):1293-1309, 2003. DOI:10.1016/S0008-8846(03)00039-5

[29] W. Zhu, J. J. Hughes, N. Bicanic, C. J. Pearce. Nanoindentation mapping of mechanical properties of cement paste and natural rocks. Materials Characterization 58 (11-12):1189-1198, 2007. DOI:10.1016/j.matchar.2007.05.018

[30] L. Sorelli, G. Constantinides, F.-J. Ulm, F. Toutlemonde. The nano-mechanical signature of Ultra High Performance Concrete by statistical nanoindentation techniques. Cement and Concrete Research 38 (12):1447-1456, 2008. DOI:10.1016/j.cemconres.2008.09.002. 